\title{
WORLD POPULATION PROSPECTS
}

\begin{abstract}
RoBert C. COOK*
Mr. Cook traces the development of world population and birth/ death rates from man's nascency over 600,000 years ago until the present time. After projecting that the present world population will double by the year 2000, the author discusses how this "explosion" may well be the most urgent problem facing mankind over the next quarter-century. He concludes that although efforts during the past five years have been encouraging, nevertheless no one knows just how the great mass of people in the underdeveloped countries can be motivated to control their fertility.
\end{abstract}

Anthropologists and paleontologists differ by hundreds of thousands of years as to the date when a recognizably human creature first appeared on earth. The classical discoveries of anthropologist L. S. B. Leakey have definitely established the existence of human prototypes in East Africa, which may mark the beginnings of the species. ${ }^{1}$ For the purposes of demographic estimates, however, perhaps the most reasonable date to fix upon for the emergence of man is some 600,000 years before Christ. ${ }^{2}$

During the first half million years or more of man's rather precarious foothold on Earth, his numbers were modest and our knowledge of him is extremely meager. ${ }^{3}$ He was a gatherer of food, typically, not a producer. Dependent upon wild game and fruits, he was a nomad, gravitating to tribal groupings small enough to remain permanently mobile. He was completely subject to all of the vagaries of the weather and the ecological cycle of the game on which his existence depended. Food shortages were usually endemic, and the ravages of epidemics were routine-although the wide dispersal of the population tended to localize these hazards. Nevertheless, the picture that emerges is one in which births and deaths were roughly balanced, with births holding a narrow margin throughout the centuries. Had this not been true, man would long ago have become extinct.

How many births there actually were, or what the rate of birth per thousand was, will always remain a demographer's puzzle, for Paleolithic man left no population records on the walls of his caves-

* President, Population Reference Bureau.

1 Leakey, "The Origin of the Genus Homo," an illustrative lecture presented at the Darwin Centennial at the University of Chicago, Chicago, Ill., Nov. 25, 1959, in 2 Sol Tax, "The Evolution of Man," Evolution after Darwin 17 (1960).

2 See Population Bulletin, XVIII, No. 1, February 1962.

3 For an excellent survey of archeological demography, see Pearl, The Natural History of Population (1939). 
and few bones to count. Nonetheless, it is conjectured that in the Old Stone Age, between 600,000 and 6000 B.C., numbers grew to about five million and the birth rate was close to fifty per thousand.

Sometime around 6000 B.C., man began to be a producer as well as a gatherer of food. In the Near East, he had already passed the stage of the most primitive village-farming communities which grew out of the earliest agriculture. Here, despite the rigors of life, many "island civilizations" of a high cultural level prospered for a time in the rich river valleys of Egypt and Asia and then vanished. Populations apparently grew rapidly during the emergence of a "golden age," and then declined during the following period of regression and decay. In the most varied contexts, this cycle of growth and decline appears to have been repeated for millennia. Even in China, the location of man's most stable culture, this seems to have been the recurrent pattern.

In any event, the competent consensus is that by the time of Christ, near the midpoint in the cycle of growth and decline of the Roman Empire, the population of the world amounted to some $250,000,000$ human beings. ${ }^{4}$ During the next sixteen centuries, however, the picture of population growth remains hazy. ${ }^{5}$ There is archeological evidence of sharp decline in numbers on the European continent between the years 800 and 1000 A.D. With the final repulsion of the barbarian invasions in the 10th century, there appears to have been a gradual seesawing upward in numbers, ${ }^{8}$ but the conditions of life for most of the human species ranged from deplorable to appalling. George Sarton has given us a vignette of the poverty, misery, and deprivation of life in 13th-century Italy: ${ }^{7}$

4 For an excellent summary of the available information on population growth from ancient to modern times, see U.N. Dep't of Economic and Social Affairs, "Determinants and Consequences of Population Trends," ch. 2, at 5, 20 (ST/SOA/Ser. A/17) (1953).

5 The scientific study of population was not undertaken until the latter part of the 17 th century. In 1662 , John Graunt, a British mathematician, analyzed the registers of baptisms and burials that had been kept regularly by the clerks of the parishes in and around London since 1603 and computed therefrom sex ratios, the ratio of births to deaths, fertility ratios, and other broad aspects of population growth. Graunt, Natural and Political Observations Made Upon the Bills of Mortality (1662). And, in 1693, Edmund Halley, the astronomer who plotted the orbit of the comet that bears his name, constructed the first empirical life-expectancy table, based on data gleaned from church records in Breslau, Silesia. Halley, "An Estimate of the Degrees of Mortality of Mankind," in 17 Philosophical Transactions of the Royal Society of London 596 (1693).

B Chevalier, "Towards a History of Population," in Population in History (D. V. Glass \& D. E. C. Eversley ed. 1965).

7 Sarton, Introduction to the History of Science 712 (1931). 
An interesting example of this struggle was given in the period under consideration by the nonconformists who preached the Eternal Evangel of Joachim of Floris. Their religious and social radicalism was condemned by the Church in 1255 , but not suppressed. To stop the rebellion of those passionate hearts it would have been necessary to cure the unspeakable evils of the time, and this was beyond the power of any church. The fact is, social and spiritual conditions were terrible, the lot of the poorer people (i.e., of the great majority) was exceedingly miserable, personal security was very low, there was no hope for man but what the Church could give him, and if the priests disappointed him his own soul must create a new faith or share his body's starvation. A more striking revolt even was that of the Battuti, whole bands of halfnaked men who crossed the towns scourging themselves by way of penitence, self-debasement, and edification. Their exaltation was as contagious as a disease, and their bands increased in numbers not only in Italy but in many other countries, spreading ecstasy, dissatisfaction, and terror everywhere. The fervor of the Italian Battuti manifested itself also in poetical form, and we owe to its inspiration one of the greatest poets of the Middle Ages, Jacopone da Todi. I wish that the scholars who magnify every evil of our own days and idealize the past beyond recognition would bear in mind these pathetic and frightful processions of Battuti. A spiritual revolt of such magnitude, and characterized by such frenzy, can only be explained by the intolerability of social circumstances.

In the next century, the Black Plague entered Europe through Italy bringing with it a horror which shocked even a civilization accustomed to suffering. The plague was not, however, a unique phenomenon. There was an average of six major famines per century in medieval Europe, and bubonic plague hit in waves about every 25 years after 1348 , with gradually decreasing severity. Still, world population growth continued, albeit erratically, and about 1650 , it is believed to have reached the $500,000,000$ mark. $^{8}$

The 17th century is an important base mark in the history of European population growth-this is the point where the growth of population began a slow and inexorable upward climb. ${ }^{9}$ Several factors seem to have contributed to this phenomenon. The frightful famines and epidemics that marked the Middle Ages had decreased significantly by this time, although hunger and disease were still widespread. The discovery of the New World, the development of the scientific method,

8 See note 4 supro.

9 See Carr-Saunders, World Population: Past Growth and Present Trends, (1936); Willcox, "Increase in the Population of the Earth and of the Continents since 1650," in 2 International Migrations 38 (Willcox ed. 1931). 
and the application of concomitant new knowledge to technology gradually began to have an effect. Moreover, after a century of belligerency, warfare throughout the European continent diminished in the 18th century. The numbers of people steadily increased.

Much of the increase in numbers in the 18th century had been due to a decrease in the rate of death. Improved agricultural technology and better transportation, which helped to eliminate local pockets of famine, made it possible to support greater numbers of children to maturity. Against this background, Jenner's dramatic discovery of vaccination just as the 19th century began, applied scientific method to biology and initiated a new era. One of the major epidemic killers was banished from Europe in only a few decades-diminishing the number of deaths by smallpox in London from over 2,000 in 1803 to 622 only two years later.

The late Norman Himes coined the term "vital revolution" to mark the beginning of the era when man began to control the pattern of his dying and the pattern of his being born. With drastic declines in mortality, a level of fertility which throughout earlier ages was essential to survival, suddenly became an anachronism and a danger to the welfare of the family, the nation and the entire human race. Until very recently, the alarming implications of a growing imbalance between rapidly declining death rates and traditional birth rates has not been recognized. Only within the last two generations has the dynamic interplay between mortality and fertility begun to receive the attention it obviously deserves. Only with the alarming situation in the world today where 55 million deaths a year are far outbalanced by 120 million births has fertility control become a matter of acute concern to governments and leaders of many nations.

Throughout the preceding hundreds of thousands of years, the survival of the human species had been a touch-and-go affair, in which high mortality had been balanced by high fertility. Reproduction somewhere near the physiological limit of the human female-a relatively slow breeder, even among mammals-had been essential to the survival of any culture. In most countries of Europe, and certainly in the United States, a high birth rate was maintained throughout most of the 19th century, producing, in conjunction with the falling death rate, a rate of population increase unprecedented up to that time. World population passed the 1 billion mark for the first time about the middle of the 19th century.

There is scattered evidence that by 1750 -fifty years before the first successful attack on death rates had taken place-birth rates had begun to decline in France. The reasons are not very apparent, al- 
though there is an impressive accumulation of literature attempting to explain what happened. ${ }^{10}$ The revolution in fertility was initiated by a semi-ritualized form of exposure. A significant proportion of the baptisms recorded in Paris in the middle of the 18th century was of foundlings, among whom the mortality was extremely high. The next step was a reduction in the birth rate. This occasioned grave alarm in certain quarters. The downward trend continued for over a century.

Ireland, between the 1780's and 1845 experienced a population growth which was nothing short of phenomenal. From a calculated estimate of $3,480,000$ in 1767 , it grew to $8,300,000$ by $1845 .^{11}$ Such growth was made possible both by reclamation of new land for farming and by the switch from grazing to arable agriculture. The major factor in the rapid increase was the introduction of the potato in the mid-17th century. This made possible the production of large amounts of food from very small plots. Thus, tenant holdings were subjected to multiple divisions, each providing the basis for a new family and early marriage. ${ }^{12}$ Such vigorous population growth, however, was checked in the mid-19th century by the classic Malthusian "positive check": famine. For three successive years, the potato crop was a failure. Through deaths and emigration, the famine cost Ireland a fifth of her population in five years. ${ }^{13}$ Even before famine struck, the Irish had taken steps to halt their rate of population growth. They adopted, informally and in opposition to the Church and the patriots, the custom of late and few marriages. This has been rigidly maintained and has continued to the present day. ${ }^{14}$

It is interesting to note that these first instances of a falling national birth rate were found in Roman Catholic countries. The birth rate in England and the Scandinavian countries, by way of contrast, did not begin to decline until after 1850 . Thereafter, the pattern of birth limitation extended steadily southward, until today it covers the entire European continent. In North America and other places colonized from northern Europe, this same cycle was later repeated. ${ }^{15}$

10 See Spengler, France Faces Depopulation (1938).

11 See Cook, Human Fertility: The Modern Dilemma 58-59, 93-94 (1951); K. H. Connell, "Land and Population in Ireland 1780-1845," Population in History 423-33 (D. V. Glass \& D. E. C. Eversley ed. 1965).

12 Connell, op. cit. supra note 11, at 430 .

13 Id. at 433.

14 The contrast between marriages of young women in the United States and Ireland is striking. In 1951, the proportion of woman of 20 to 24 years of age in the United States who were married was 67.7 percent; in Ireland, it was $17.7 \%$. "Demographic Significances," 6 Eugenics Q. 65 (1959).

15 For information concerning current birth rate trends, see the "Population and Vital Statistics Reports" which are published quarterly by the United Nations. 
In all of these countries, this "demographic transition" has typically followed a rather leisurely course. First, the death rate begins to decline; then, after an interval of a generation or more, the birth rate has declined. This trend has not been the result of any formal action on the part either of the government or of private agencies-indeed, it has sometimes run counter to governmental pro-natalist policies. It appears rather to have reflected the general recognition that with the chances of survival of progeny steadily improving, a level of fertility urgently necessary when a third, a quarter, or even a half of the children died in infancy or childhood was no longer in the best interest of the family. Too large a brood put a serious burden on the family economy and impaired the chances of all the children to get an adequate education and a good start in life.

A century and a half after the onset of the vital revolution, the demographic situation of the world abounds in contrasts. As may be seen in the tables at the end of this article, world population now stands roughly at 3.4 billion. If the present trend of growth continues, world population would reach 7.4 billion by the year 2000 , more than doubling in 34 years. It is ardently to be hoped that the increasingly acute world-wide concern with the devastating effects of such rapid growth will result in effective action to control fertility and that the population a third of a century hence will be far below this total.

What is equally as disturbing as the spiralling population growth itself is the great disparity between nations and regions in rate of growth. During the next decade, present trends will tend to divide the world even more markedly into two distinct groups:

1. The demographically stable, industrialized "have" countries, enjoying high levels of living, where effective fertility regulation either exists or is developing. This includes all of Europe, the Soviet Union, North America, the temperate-zone countries of Latin America, Oceania, and Japan. Birth rates in these countries range from 17 to $25,,^{16}$ while death rates range from 8 to 12 .

2. The demographically unstable, "have-not" countries that are now struggling toward economic development, are those in which almost two-thirds of the world's people live. In this area, as yet, there is no effective regulation of fertility. Birth rates range between 38 and 50. Death rates do not vary so dramatically from those in the developed countries because recent declines have largely eliminated the high mortality of the past. They mostly range from 10 to 30 . This includes all of Asia (except Japan and Israel), tropical Latin America, and most of Africa.

16 Birth and death rates are per thousand of total population in a given year. 
The United Nations estimates revealed that in the next 35 years over 85 percent of the increase is expected to be in the high-birth-rate, "developing" countries of Asia, Africa, and Latin America.

Projections to the year 2000, based on current trends, indicate that four fifths of the world's people will then be living in these regions. North America and Europe (including the USSR) will have shrunk to less than one fifth of the total. World projections are somewhat moot because of the big question regarding Mainland China.

The ranking of the ten largest nations will also show some interesting changes by the year 2000. In 1965, the list included five "developed" countries. By 2000, this number may be reduced to three, with West Germany and the United Kingdom being replaced by Nigeria and Mexico. The total population for the "top ten" nations will grow to 4.7 billion, if present trends continue.

In the light of present world food supplies, such population increases, concentrated as they are in economically underdeveloped areas, are nothing short of calamitous.

The Food and Agriculture Organization of the United Nations has estimated that world food production must be almost doubled by the year 2000 just to maintain present gravely inadequate levels of consumption. The current crisis in India grimly underlines how shockingly inadequate are present levels of consumption in many areas of the world. Of the present world population, the FAO calculates, 10 to 15 percent is undernourished and up to half suffers from some degree of hunger or malnutrition, or both. United Nations' targets for nutritional improvement would involve increasing total food supplies in the developing countries to four times the recent level. ${ }^{17}$

The desperate world situation in nutrition was described at the U.N. World Population Conference in Belgrade in September 1965. The Director-General of one of the U.N. Special Agencies-the Food and Agriculture Organization-for the third time in recent months warned that food production is not keeping up with population growth. Dr. Sen said in part:

It is now less than seven years since there was any appreciable increase in food production per head of the world's population, seven very lean years for the developing countries. In two regions in particular, the Far East and Latin America, per capita production is still less than it was before the war, more than a quarter of a century ago. Many countries in these regions have been able to maintain their wholly inadequate dietary levels only by reducing exports, or

17 Food and Agriculture Organization of the United Nations, The State of Food and Agriculture 19656 (1965). 
by increasing imports of food, including in some cases a very heavy dependence on food aid.

$$
\text { *** }
$$

The general outlook is indeed alarming. In some of the most heavily populated areas the outbreak of serious famines within the next five to ten years cannot be excluded. And it is simple arithmetical conclusion that if food output everywhere just kept pace with population growth at the present level of consumption, by the end of this century the number of people who would be subject to hunger and malnutrition would be double what it is today.

A recent U.S. Department of Agriculture report sees very little prospect of the quick increase in world agricultural yield needed to meet this alarming situation:

Given the projected high population growth rates of nearly all countries in Asia, Africa, and Latin America, the limited possibilities for expanding the cultivated area in most of the densely populated countries, and the lack of success in generating a yield takeoff, it does not appear likely that the downward trends in per capita food output now in evidence in these regions can be easily arrested. Barring a rise in the death rate due to widespread malnutrition in these regions, projections show the fastest population increase in history over the next 10 years. Failure to arrest the downward trend in per capita food output in these regions will leave two alternatives: (1) a continuing decline in consumption levels (narrowing the already thin margin between current consumption levels and survival levels); or (2) growing dependence on food imports-if imports are available.

That a concerted effort is urgently required to expand world food production is indisputable. It cannot be too strongly emphasized that -essential though it be-a crash program of agricultural improvement cannot permanently cure the hunger of a billion people. There must be developed-with all speed-effective means to check the rate of population growth.

There is, of course, no question that the growth of population will be slowed. The alternatives are whether that slowing will come through famine, war, and epidemics-the cruel, though effective, Malthusian positive checks - or through human agency, to bring birth rates into balance with modern death rates. We dare not ignore the magnitude of this undertaking. Currently there are about 120 million births in the world and 55 million deaths. The reduction of births by 20 to 30 million a year presents an absolute minimum objective. Time is short, as James Reston, the distinguished commentator of The Nere York Times recently put the matter:

It would be impossible to overstate the anxiety felt here about the political trouble ahead for the overpopulated and undernourished 
countries of the world. Already there is developing a new kind of class warfare between the rich and the poor nations, and despite the biomedical and political advances in some countries, the total problem is getting worse instead of better.

Faced with the grim aspect of these alternatives, world opinion on fertility control has shifted remarkably in the past few years. As recently as 1959, President Eisenhower spoke out against any government activity in the population field: "I cannot imagine anything more emphatically a subject that is not a proper political or governmental activity or function or responsibility."

Four years later, President Eisenhower retracted that statement in an article in the Saturday Evening Post of October 26, 1963. In it, he said:

When I was President, I opposed the use of Federal funds to provide birth-control information to countries we were aiding ... it may be that I was carrying that conviction too far ... we should not make birth-control programs a condition to our foreign aid, but we should tell receiving nations how population growth threatens them and what can be done about it.

From the first, President Johnson has been aware of the magnitude of the population problem. In the 1965 State of the Union Message, he said: "I will seek new ways to use our knowledge to help deal with the explosion in world population and the growing scarcity in world resources." Later that year, in his United Nations Twentieth Anniversary speech, he said: "Let us . . . face forthrightly the multiplying problems of our multiplying populations and seek answers to this most profound challenge to the future of the world."

Spurred partly by Presidential interest, and partly by the separate concern of members with the problem, Congress has in the past two years taken an active interest in the world population situation and its possible amelioration. For the first time in its history, Congress enacted legislation dealing with the population problem in January 1964. This was embodied in the foreign aid bill authorizing the Agency for International Development to conduct "research into problems of population growth."

The Supreme Court, in 1965, in striking down Connecticut's antibirth control statutes, opened up greater possibilities for private and governmental participation in research and clinical support for family planning programs. In addition, it cleared the way for Congressional consideration of possible legislation in this field.

In June 1965, the Subcommittee on Foreign Aid Expenditures of the U.S. Senate, under the chairmanship of Senator Ernest Gruening 
began extensive hearings on the population crisis in reference to a reorganization of the Department of State and of the Department of Health, Education, and Welfare to deal with the problems involved. Those hearings are still in progress.

In February of 1966, the Committee on Agriculture of the House of Representatives held extensive hearings in conjunction with Chairman Harold D. Cooley's bill to initiate a World War on Hunger. In those hearings, detailed testimony on the population problem was heard. As a result of these hearings and of continued interest by the Administration, food-for-freedom programs now being considered by Congress incorporate the use of local currencies which accrue from agricultural sales abroad for family planning programs in countries requesting them.

Several administrative agencies are already actively involved in family planning. Under the administration of John Gardner, HEW has begun to distribute funds to the various states to help support whatever birth control programs the states provide. The Office of Economic Opportunity, the chief anti-poverty agency, also makes some grants to family planning clinics. Money from this latter source, however, is restricted in amount and in manner of expenditure. Recipients of OEO funds are forbidden, among other things, to advertise birth control aids, or to supply unmarried women or women not living with their husbands with contraceptives.

AID is giving increasing attention to family planning in its overseas missions. According to David Bell's testimony at the Senate committee hearings on population, AID's dollar obligations for fiscal year 1965 were about 2 million dollars, for fiscal year 1966 about 5.5 million dollars, and for 1967 are expected to be approximately 10 million dollars. It has instructed each Mission to have an officer informed on the population problems of the country concerned, and it will entertain requests for technical assistance to local family planning programs, not including, however, the supplying of actual contraceptive devices.

Overseas, recent events in population control have been even more encouraging. Notably, Korea and Taiwan are running family planning programs on a country-wide basis and achieving some success. Taiwan's program, less than two years old, has already reached one in every twelve women in the childbearing years. The Korean effort, sponsored by the government and supported by the highest per capita funds of any program in 1965 , had reached almost as high a percentage of its women by the end of the year, and in addition, had performed a substantial number of vasectomies. Elsewhere in Asia, both India and 
Pakistan have drawn up ambitious plans for government-sponsored family-planning programs, designed to reach into the countryside. In the Philippines, the Manila Health Department has trained a number of doctors and nurses in birth-control techniques, and family-planning equipment has been distributed to some ten health centers.

In 1965 Turkey repealed its old laws forbidding any kind of fertility control and concomitantly passed a Family Planning Law to implement a national program through the Ministry of Health. Of the North African countries, Tunisia is the most advanced on population control and has announced that an official national program would start in January of 1966.

In Latin America, demographic research is going on in many areas. In Chile, a voluntary national committee backed by the National Health Service offers personnel and family-planning services to much of the Santiago population. Other nations, Peru, Venezuela, San Salvador, are considering the possibility of official action in the population field.

In addition to separate national efforts, United Nations organizations have recently reached important decisions in the population field. In July 1965, the Economic and Social Council voted to offer technical assistance for birth control. The UNICEF Governing Council, in 1965, requested its director to prepare a statement on possible UNICEF activities in the population field. ${ }^{18}$

On May 18, 1966, the World Health Organization rejected a United States proposal that asked it to assume international leadership in developing family planning as an answer to the population explosion. Instead, it resolved that WHO's role was to "advise members, upon request, in the development of activities in family planning." The significant point in this action was that the delegates from 67 nations voted affirmatively. Among them were most of the Communist and Catholic countries which had for years effectively prevented any U.N. action in the population field.

A recent publication from the University of Chicago Press presents a superb summary of everything now happening in the field of population control. It will be useful to any seeking further information on the problem and its possible solutions. ${ }^{19}$

\section{CONCLUSTON}

The developments in the past five years in the population field are unprecedented and very hopeful. The climate of thought in this

18 The Population Council, "Recent Events in Population Control," Studies in Family Planning, No. 9 (January 1966).

19 Berelson et. al., Family Planning and Population Programs (1966). 
and other countries has changed completely. Before that, fear and indifference frequently blanketed any discussion, and action programs were taboo; now activity is developing in many countries around the world.

This is most encouraging-but it cannot be too strongly emphasized that what has taken place so far is only the prologue to a comprehensive plan to come to grips with this most important problem. The "population explosion"-so-called-is definitely a human artifact. It has taken place because the genius of the human mind has changed utterly the pattern of dying. In the controlled fertility area in the Western industrial world, spontaneous adjustments were made during the past century without any formal action by any governments or private agencies. The big shift in birth rates took place before birth control became a controversial issue about 1920 .

What has happened is very much to the good. But as matters stand today, nobody knows just how the two billion people in the traditionally-minded agrarian countries can be motivated to control their fertility. This is the crux of the problem. The adoption of birth control programs by governments is indeed an important step. The implementation of these programs is another and very difficult matter.

The projections of population growth to the year 2000 are based on assumptions as to how fast control of fertility can be initiated in the crisis countries. These projections are in a sense "demographic radarscope" warnings of trouble ahead. A world inhabited by 7 billion people 34 years hence is not a pleasant world to contemplate. Whether the genius of the human mind which gave mankind a formula for averting death can find ways to avert this disastrous by-product of this great discovery is perhaps the premier question the human race confronts today. 


\begin{tabular}{|c|c|c|c|c|c|c|c|c|c|c|c|c|c|}
\hline \multicolumn{14}{|c|}{ Population Projections: World and Major Areas } \\
\hline \multirow{3}{*}{ World and Mrajor Areas } & \multicolumn{13}{|c|}{ Population in Mfillions } \\
\hline & $\begin{array}{l}\text { mid- } \\
1965\end{array}$ & & 1970 & & 4 & 1980 & & & 1090 & & & 2000 & \\
\hline & $\begin{array}{l}\text { esti- } \\
\text { mated } \\
\text { popu- } \\
\text { lation }\end{array}$ & $\begin{array}{l}\text { con- } \\
\text { tinued } \\
\text { trends }\end{array}$ & medium & Ior & $\begin{array}{l}\text { con- } \\
\text { tinued } \\
\text { trends }\end{array}$ & medium & low & $\begin{array}{l}\text { con- } \\
\text { tinued } \\
\text { trends }\end{array}$ & medium & Iow & $\begin{array}{l}\text { con- } \\
\text { tinued } \\
\text { trends }\end{array}$ & aredium & $10=$ \\
\hline World & 3,308 & 3,626 & 3,574 & 3,515 & 4,487 & 4,269 & 4,071 & 5,704 & 5,063 & 4,659 & $-7,410$ & 5,005 & 5,265 \\
\hline $\begin{array}{l}\text { Asis } \\
\text { East Aria } \\
\text { South Asia } \\
\text { Africa } \\
\text { Latin Amerien } \\
\text { Europe } \\
\text { Northern Americs } \\
\text { Ocennia } \\
\text { U.B.8.R }\end{array}$ & \begin{tabular}{|r|}
1,842 \\
807 \\
975 \\
311 \\
248 \\
443 \\
215 \\
17 \\
234
\end{tabular} & $\begin{array}{r}2,033 \\
941 \\
1,092 \\
348 \\
284 \\
160 \\
230 \\
18 \\
253\end{array}$ & $\begin{array}{r}2,000 \\
910 \\
1,090 \\
346 \\
282 \\
454 \\
227 \\
19 \\
246\end{array}$ & $\begin{array}{r}1,959 \\
892 \\
1,077 \\
344 \\
278 \\
450 \\
222 \\
19 \\
243\end{array}$ & $\begin{array}{r}2,557 \\
1,139 \\
1,418 \\
453 \\
357 \\
496 \\
272 \\
22 \\
295\end{array}$ & $\begin{array}{r}2,404 \\
1,035 \\
1,366 \\
449 \\
374 \\
479 \\
262 \\
23 \\
278\end{array}$ & $\begin{array}{r}2,279 \\
1,316 \\
434 \\
352 \\
467 \\
248 \\
22 \\
269\end{array}$ & $\begin{array}{r}3,317 \\
1,419 \\
1,893 \\
620 \\
537 \\
533 \\
325 \\
27 \\
345\end{array}$ & $\begin{array}{r}2,840 \\
1,163 \\
1,677 \\
5 \$ 7 \\
4 S 3 \\
504 \\
306 \\
27 \\
316\end{array}$ & $\begin{array}{l}2,006 \\
1,006 \\
1,570 \\
546 \\
429 \\
452 \\
274 \\
25 \\
297\end{array}$ & $\begin{array}{r}4,401 \\
1,803 \\
2,508 \\
880 \\
756 \\
571 \\
353 \\
33 \\
402\end{array}$ & $\begin{array}{r}3,307 \\
1,234 \\
2,023 \\
763 \\
624 \\
527 \\
354 \\
32 \\
353\end{array}$ & $\begin{array}{r}2,369 \\
1,114 \\
1,855 \\
684 \\
514 \\
491 \\
294 \\
27 \\
316\end{array}$ \\
\hline
\end{tabular}

from Population Bulletin, October 1965

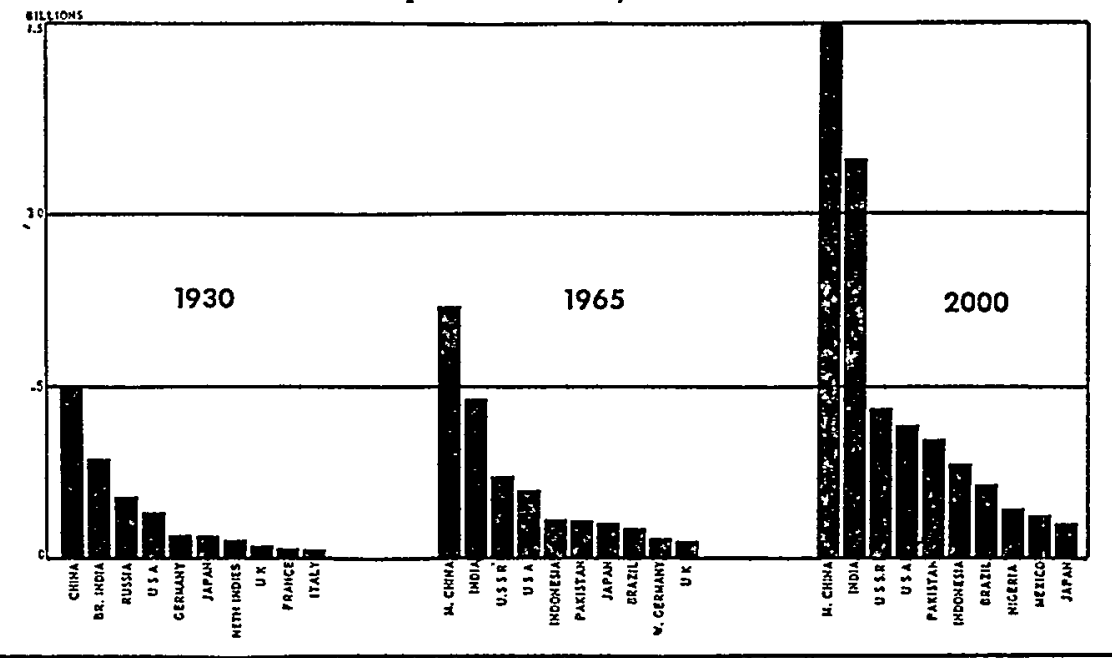

"Top Ten" Nations in Population: 1930, 1965, 2000. Mainland China and India will go over the billion mark by 2000. Japan, because of its slow rate of population growth, will drop back to tenth place. By 2000 Mexico and Nigeria will have entered the ranks of the "Top Ten." 